\title{
Pengembangan E-Learning untuk Pembelajaran Sekolah Nonformal
}

\author{
Fahmi Irfan \\ Program Studi Pendidikan Matematika \\ Fakultas Keguruan dan Ilmu Pendidikan \\ Universitas Pekalongan \\ fahmiirfan56@gmail.com
}

\begin{abstract}
Abstrak
Pendidikan nonformal merupakan jalur pendidikan di luar jalur pendidikan formal yang dibuat oleh pemerintah untuk memfasilitasi masyarakat yang tidak dapat menempuh pendidikan formal. Waktu pembelajaran pada pendidikan non-formal jauh lebih sedikit dibandingkan dengan pendidikan formal. Hal ini jelas menjadi masalah bagi masyarakat yang mengikutinya. Selain itu, kurangnya inovasi pembelajaran juga menjadi kendala dalam sekolah nonformal.

Pada penelitian ini dikembangkan E-learning berbasis Moodle yang di dalamnya memuat materi pembelajaran, tugas, dan soal tes. Penelitian ini bertujuan untuk mengembangkan E-learning yang valid dan praktis. Penelitian pengembangan ini menggunakan model pengembangan Thiagarajan dkk. Tahapan-tahapan dalam penelitian ini adalah pendefinisian, perancangan, dan pengembangan.

Berdasarkan hasil penelitian, diperoleh E-learning yang dapat menambah waktu pembelajaran dan memberi inovasi dalam pembelajaran sekolah non-formal. Sementara itu, diperoleh pula rata-rata total aspek dari semua validator adalah 4,19. Menurut kriteria validasi maka dapat disimpulkan bahwa E-learning yang dikembangkan termasuk dalam kategori valid. Setelah E-learning dinyatakan praktis, kemudian E-learning tersebut di ujicobakan di kelas XI PKBM Al-Hikmah Tangkil Kulon. Berdasarkan rata-rata angket yang diberikan kepada warga belajar setelah dilakukan ujicoba, didapatkan hasil $\bar{X}=3,31$. Berdasarkan kriteria kepraktisan maka dapat disimpulkan bahwa E-learning yang dikembangkan praktis. Hal ini berarti E-learning berbasis moodle yang dikembangkan valid dan praktis.
\end{abstract}

Kata Kunci : E-learning, pembelajaran, nonformal.

\begin{abstract}
Non-formal education is a path of education outside of formal educational line made by the government to facilitate people who can't take a formal education. Learning time on non-formal education is much less compared to formal education. Therefore, it becomes a problem for the people who take a non-formal education. In addition, the lack of learning innovations also become constraints in non-formal schools.

The study developed E-learning based Moodle which contains learning materials, assignments, and the question of the test. It aimed to develop a valid and practical E-learning. This development research used the development model of Thiagarajan et al. The stages in this research were defining, designing, and developing.

Based on the results of the study, obtained E-learning which could increase the learning time and provide innovations in non-formal school learning. Meanwhile, the average total aspect of all validators was 4.19. According to the validation criteria, it could be concluded that the developed E-learning was included in the valid category. After E-learning practical stated, then the E-learning was tested in XI graders of PKBM AlHikmah Tangkil Kulon. Based on the average questionnaire which was given to the learning community, the results were obtained $\bar{X}=3,31$ after testing. Based on the criteria of practicality, it could be concluded that the developed E-learning was practical. This meant that the developed E-learning based Moodle was valid and practical.
\end{abstract}

Keywords: E-learning, Learning, Non-formal. 


\section{Pendahuluan}

Pendidikan sesungguhnya memiliki peran yang sangat penting dalam kehidupan berbangsa dan bernegara, yakni dalam upaya menciptakan sumber daya manusia yang berkualitas. Pendidikan merupakan suatu faktor kebutuhan dasar untuk setiap manusia, karena melalui pendidikan upaya peningkatan kesejahteraan rakyat dapat diwujudkan. Pendidikan mempengaruhi secara penuh pertumbuhan ekonomi suatu negara. Hal ini bukan saja karena pendidikan akan berpengaruh terhadap produktivitas, tetapi juga akan berpengaruh pada kemampuan masyarakat. Pendidikan dapat menjadikan sumber daya manusia lebih cepat mengerti dan siap dalam menghadapi perubahan dan pembangunan suatu negara. Pendidikan tidak hanya berperan besar dalam kemajuan bangsa, melainkan juga berkaitan dengan pasar bebas yang semakin kompetitif. Pendidikan hendaknya dipandang dapat mengakomodir masyarakat agar suatu negara memiliki manusia-manusia yang berkualitas. Melalui pendidikan dapat menciptakan tenaga kerja yang tidak hanya kaya akan pengetahuan teoritis melainkan juga praktis, penguasaan teknologi, dan memiliki keahlian khusus.

Oleh karena itu pendidikan dirasa sangat penting untuk membangun Indonesia yang lebih berkembang dalam segala aspek kehidupan. Menurut UU no 2 tahun 1989 pendidikan di Indonesia diselenggarakan melalui dua jalur, yaitu jalur sekolah dan jalur luar sekolah. Pendidikan jalur sekolah atau yang sering kita kenal dengan pendidikan formal adalah jalur pendidikan yang terstruktur dan berjenjang yang terdiri atas pendidikan dasar, pendidikan menengah, dan pendidikan tinggi. Namun ketika seseorang memilih pendidikan formal, kemudian berhenti pada suatu titik tertentu karena pendidikan formal dibatasi kesempatan dan waktu, atau seseorang tidak diperkenankan untuk memperoleh pendidikan formal karena usia, maupun karena putus pendidikan formal ( drop out) dan karena berbagai hal lain sehingga seseorang tersebut tidak memiliki kesempatan untuk mengikutinya, maka pada saat itulah diperlukan sebuah solusi agar setiap masyarakat tetap bisa menikmati pendidikan meski dengan segala keterbatasannya. Pendidikan nonformal adalah pendidikan yang diselenggarakan melalui jalur luar sekolah. Jenis pendidikan inilah yang dapat menjadi solusi dari permasalahan tersebut. Pendidikan nonformal dapat menampung anak-anak putus sekolah dan memberikan mereka pendidikan sampai setara SMA/MA, hal ini sejalan dengan program pemerintah mengenai wajib belajar 12 tahun bagi masyarakat Indonesia yang

tertuang dalam Permendikbud no 19 tahun 2016 tentang Indonesia Pintar. Dengan diadakannya wajib belajar 12 tahun bagi masyarakat Indonesia pemerintah berharap akan terciptanya generasi penerus bangsa yang dapat membawa Negara ini menjadi Negara maju. 
Dalam UU no 20 tahun 2003 tentang Sisdiknas istilah pendidikan formal, nonformal, dan informal dipergunakan kembali. Dijelaskan bahwa pendidikan nonformal adalah jalur pendidikan di luar pendidikan formal yang dapat dilaksanakan secara terstruktur dan berjenjang. Sedangkan menurut Paulo Freire (dalam Mustofa, 2009:34) Pendidikan nonformal adalah obat mujarab bagi seluruh penyakit pendidikan di masyarakat. Ini menunjukkan bahwa pendidikan nonformal bisa menjadi tempat bagi masyarakat yang masih ingin menikmati pendidikan tetapi tidak dapat menikmati pendidikan formal.

Ada beberapa lembaga dalam konsep pendidikan nonformal, salah satunya adalah Pusat Kegiatan Belajar Masyarakat (PKBM). PKBM adalah sebuah lembaga pendidikan yang dikembangkan dan dikelola oleh masyarakat serta diselenggarakan diluar pendidikan formal dengan tujuan untuk memberikan kesempatan belajar kepada seluruh lapisan masyarakat agar mereka mampu membangun dirinya secara mandiri dan dapat meningkatkan kualitas hidupnya (Kamil Mustofa, 2009:83). Salah satu bidang pendidikan nonformal yang diadakan oleh PKBM adalah Program Kesetaraan. Program kesetaraan melingkupi program paket A setara SD/MI, kelompok belajar paket B setara SMP/MTS dan kelompok belajar Paket C setara SMA/MA. Kelompok belajar paket C merupakan program baru di lingkungan Direktorat Jendral Pendidikan Luar Sekolah, karena program ini baru berkembang sekitar tahun 2003. Hal ini sejalan dengan ditetapkannya UU Sisdiknas No 20 tahun 2003 pendidikan kesetaraan adalah program pendidikan nonformal yang menyelenggarakan pendidikan umum setara SD/MI, SMP/MTS, dan SMA/MA yang mencakup program paket A, paket B, dan Paket C. Pendidikan Kesetaran mempunyai sebutan khusus bagi masyarakat yang mengikuti program ini, mereka tidak lagi disebut sebagai siswa, tetapi warga belajar.

Kebanyakan dari masyarakat yang menempuh pendidikan kesetaraan adalah masyarakat yang putus sekolah karena faktor ekonomi maupun dikeluarkan dari pendidikan formal ataupun masyarakat yang usianya tidak mencukupi untuk mengenyam pendidikan formal. Karena faktor-faktor tersebut masyarakat yang ikut dalam program kesetaraan yaitu anakanak putus sekolah dan masyarakat yang sudah bekerja tetapi masih ingin menempuh pendidikan. Waktu pembelajaran yang dilaksanakan oleh program kesetaraan juga disesuaikan dengan rutinitas masyarakat yang ikut di dalamnya. Sehingga waktu pembelajaran yang diadakan dalam pendidikan kesetaraan tidak seperti pendidikan formal. Pendidikan kesetaraan kebanyakan diadakan pada sore hari maupun malam hari, tetapi ada juga yang diadakan hanya pada akhir pekan, sehingga waktu pembelajaran menjadi jauh lebih singkat dibandingkan pendidikan formal. 
Seperti observasi dan wawancara yang dilakukan peneliti pada sekolah nonformal, tepatnya di PKBM Al-Hikmah Tangkil Kulon dan juga melalui angket yang diberikan kepada warga belajar di sekolah tersebut, peneliti mendapatkan beberapa permasalahan, yang pertama adalah bagi warga belajar yang tidak bekerja waktu pembelajaran yang diadakan di PKBM Al-Hikmah terasa sangat kurang karena dalam satu minggu pembelajaran hanya dilakukan selama 9 jam. Hal ini sangat jauh jika dibandingkan dengan sekolah formal, sedangkan mata pelajaran yang diajarkan di sekolah nonformal jumlahnya sama dengan sekolah formal. Masalah kedua adalah bagi warga belajar yang sudah bekerja, masalah bagi mereka adalah motivasi belajar mereka untuk mengikuti pembelajaran yang masih rendah, hal ini dapat dilihat pada saat waktu pembelajaran di sekolah bersamaan dengan waktu mereka bekerja, mereka cenderung lebih memilih untuk bekerja daripada berangkat ke sekolah. Bagi warga belajar yang sudah bekerja kebanyakan dari mereka dalam satu minggu hanya berangkat satu kali. Kedua permasalahan tersebut jelas berdampak pada saat mereka melakukan ujian, mereka sangat kesulitan dalam menjawab pertanyaan, dan dampak lebih lanjutnya adalah hasil ujian mereka yang sebagian besar masih tergolong rendah. Hal ini dapat dilihat dari ratarata hasil UNBK mereka yang masih dibawah angka 7. Selain itu untuk saat ini warga belajar tidak mempunyai buku pegangan saat pembelajaran, terkadang mereka hanya meminjam buku dari perpustakaan yang nantinya harus dikembalikan pada saat jam pembelajaran telah usai. Hal ini membuat warga belajar tidak dapat belajar pada saat mereka tidak berada dilingkungan sekolah.

Diperlukan suatu terobosan baru yang dapat mengejar ataupun membuat warga belajar tidak ketinggalan materi. Salah satu solusi yang mungkin dapat digunakan adalah menerapkan E-Learning. E-Learning adalah proses pembelajaran efektif yang diciptakan dengan cara menggabungkan konten yang disampaikan secara digital dengan jasa dan sarana pendukung pembelajaran (Manson Robin \& Frank Rennie, 2010 : xiii). Pada abad ke-21 ini tidak dapat dipungkiri bahwa internet menjadi kebutuhan pokok bagi masyarakat di semua kalangan.

Sebenarnya PKBM Al-hikmah pernah menerapkan E-learning dalam pembelajaran, pada saat itu antusias warga beajar dalam kehadiran meningkat cukup signifikan. E-Learning yang pernah diterapkan masih menggunakan system Local Area Network. Sehingga E-Learning ini sangat bergantung pada jaringan internet sekolah. Pada suatu hari jaringan internet sekolah terkena sambaran petir sehingga membuat jaringan internet beserta seluruh listrik di sekolah menjadi padam. Akibat padamnya jaringan internet disekolah E-Learning kembali tidak dapat digunakan di PKBM Al-Hikmah. Akibatnya jumlah kehadiran siswa kembali menurun. 
Menyadari hal ini peneliti berharap dapat kembali menarik minat warga belajar untuk mengikuti pembelajaran di PKBM Al-Hikmah dengan menerapkan kembali E-Learning di sekolah. Tetapi kali ini peneliti berupaya membuat E-Learning yang tidak bergantung pada jaringan internet sekolah sehingga kejadian serupa tidak terulang kembali. Meskipun peneliti ingin membuat E-Learning yang dapat diakses dimana saja, tetapi peneliti masih bisa mengontrol kapan E-Learning tersebut dapat digunakan. Contohnya, peneliti dapat memberikan tugas hanya kepada warga belajar yang pada hari itu mengikuti pembelajaran di sekolah dan menutup akses kepada warga belajar yang pada hari itu tidak berangkat. Peneliti juga dapat membuka E-Learning untuk memberikan tugas kepada warga belajar yang kehadirannya masih kurang yang nantinya tugas tersebut diserahkan langsung ke sekolah ini dilakukan untuk memberikan nilai tambahan kepada mereka. Sistem buka tutup ini dilakukan untuk meminimalisir kemungkinan warga belajar lebih memilih untuk belajar dirumah daripada di sekolah. Dengan menerapkannya E-Learning ini diharapkan warga belajar tidak ketinggalan materi meskipun waktu pembelajaran sedikit, warga belajar masih tetap dapat belajar meskipun mereka berhalangan hadir di sekolah, selain itu E-Learning juga dapat membantu tutor dan warga belajar dalam kegiatan belajar mengajar.

Adanya E-Learning ini akan membuat pembelajaran di PKBM Al-Hikmah menjadi 2 cara, yaitu : Permbelajaran tatap muka dan pembelajaran online. Pembelajaran tatap muka adalah suatu pembelajaran yang dilakukan secara langsung atau melalui tatap muka antara tutor dengan warga belajar. Sedangkan pengertian pembelajarana online (E-Learning ) yang ada pada Permendikbud no 109 tahun 2013 adalah pembelajaran yang memanfaatkan paket informasi berbasis teknologi informasi dan komunikasi untuk kepentingan pembelajaran yang dapat diakses oleh peserta didik kapan saja dan dimana saja. Dengan 2 cara pembelajaran yang diakadan di PKBM Al-Hikmah ini warga belajar akan mendapatkan pembelajaran yang lebih maksimal.

Berdasarkan uraian diatas, peneliti tertarik untuk membuat penelitian tentang pengembangan E-Learning disekolah nonformal yang berjudul "Pengembangan E-Learning untuk Pembelajaran Sekolah Nonformal"

\section{Metode Penelitian}

Menurut Sugiyono (2016: 407) dalam “Metode Penelitian Pendidikan" menjelaskan bahwa metode penelitian dan pengembangan atau dalam Bahasa Inggrisnya Research and Development adalah metode penelitian yang digunakan untuk menghasilkan produk tertentu, dan menguji keefektifan produk tersebut. Model pengembangan yang digunakan dalam 
penelitian ini adalah model menurut Sivasailam Thiagarajan, Dorothi S. Semmel, dan Melvyn

I. Semmel (1974) yang selanjutnya disebut model Thiagarajan, dimana model pengembangan terbagi menjadi 4 tahap utama yaitu 4D : Define, Design, Develop, dan Disseminate atau diadaptasi menjadi 4P, yaitu pendefinisian, perancangan, pengembangan, dan penyebaran

Melalui penelitian dan pengembangan ini, peneliti berusaha mengembangkan sebuah produk yang dapat digunakan dalam pembelajaran di sekolah nonformal. Produk yang dikembangkan dalam penelitian ini adalah E-Learning berbasis moodle. E-Learning ini diharapkan dapat membantu warga belajar di sekolah nonformal, dan juga dapat mempermudah para tutor untuk menyampaikan pembelajaran.

\section{Hasil dan Pembahasan}

Penelitian pengembangan E-learning untuk sekolah nonformal ini melalui beberapa tahap yaitu: pendefinisian (defind), perancangan (design), dan pengembangan (development). Penelitian ini bertujuan untuk mengetahui E-learning yang sesuai dengan sekolah nonformal, mengembangkan E-learning yang dapat digunakan untuk sekolah nonformal dan mengetahui kevalidan dan kepraktisan E-learning berbasis moodle untuk sekolah nonformal.

Penelitian ini diawali dengan tahap pendefinisian. Tahap pendefinisan dilakukan dengan melakukan observasi, menyebar angket dan melakukan wawancara yang bertujuan untuk mencari permasalahan yang terjadi di sekolah nonformal. Dari ketiga kegiatan tersebut didapatkan permasalahan pokok yang terjadi pada sekolah nonformal yaitu kurangnya waktu pembelajan, hal ini berdampak pada rendahnya hasil belajar warga belajar. Selain itu kurangnya inovasi dalam pembelajaran juga membuat warga belajar kekurangan motivasi untuk mengikuti pembelajaran.

Berdasarkan masalah yang ditemukan, maka dilakukan perancangan media pembelajaran untuk mengatasi permasalahan yang terjadi. Media yang dipilih berdasarkan kebutuhan warga belajar adalah E-learning berbasis moodle. E-learning yang dikembangkan dapat berisi materi pembelajaran, tugas, soal tes, chat, dan forum diskusi. Hal ini sesuai dengan yang dikemukakan Caputi dan Garrido (dalam Tiara. $2015: 2$ ) terdapat dua jenis aktivitas dalam $E$ learning yaitu aktivitas komunikasi ( e-mail, forum, konferensi, dan lain-lain) dan aktivitas eksplorasi, dimana keduanya ada dalam sebuah LMS (Learning management System).

Desain dari materi yang ada pada E-learning ini adalah pembelajaran tahap demi tahap. Warga belajar harus menyelesaikan tahap pertama untuk dapat melangkah ke tahap kedua, pertanyaan diberikan setelah warga belajar mempelajari tahap pertama, pertanyaan ini diberikan sebagai syarat warga belajar dapat melangkah ke tahap kedua dan seterusnya. Hal ini bertujuan supaya warga belajar dapat benar-benar memahami tahap demi tahap sebelum 
melangkah ke tahap selanjutnya. Selain itu tampilan soal tes dibuat semirip mungkin dengan tampilan soal pada saat UNBK. Hal ini bertujuan untuk membiasakan warga belajar menggunakan sistem ujian seperti UNBK.

E-learning yang sudah selesai dibuat kemudian divalidasi oleh 8 validator yang terdiri dari 3 dosen dan 5 guru. Hasil validasi menyatakan sebagian besar aspek sudah sesuai dengan kebutuhan, tetapi pada aspek tampilan media, validator berpendapat bahwa tampilan media masih harus diperbaiki supaya lebih menarik lagi. Setelah dilakukan perhitungan angket dari 8 validator, diperoleh rata-rata total validasi semua aspek dari validator adalah $\mathrm{V}_{\mathrm{a}}=4,19$. Menurut kriteria validasi maka dapat disimpulkan E-learning berbasis moodle dinyatakan valid dengan syarat revisi sesuai masukan dari validator. Setelah dilakukan revisi E-learning berbantuan moodle layak diujicobakan.

Ujicoba dilakukan untuk memperoleh E-learning yang praktis dan dapat digunakan dalam pembelajaran. Ujicoba dilakukan di kelas XI PKBM Al-Hikmah dengan jumlah warga belajar yang mengikuti ujicoba sebanyak 21 orang. Warga belajar menilai masih terdapat kekurangan dalam penataan menu pilihan dan juga perlu adanya penambahan gambar pada beberapa materi. Berdasarkan hasil perhitungan rata-rata total aspek didapatkan hasil $\bar{X}=3,31$. Berdasarkan kriteria kepraktisan, maka E-learning berbasis moodle dinyatakan praktis.

Berdasarkan uraian diatas dapat ditarik kesimpulan bahwa E-learning berbasis moodle yang dikembangkan valid dan praktis dan menjawab rumusan masalah dalam penelitian ini bahwa E-learning berbasis moodle dapat mengatasi masalah kurangnya waktu pembelajaran di sekolah nonformal. Hal ini sesuai dengan pendapat yang di sampaikan oleh Asyhar (dalam Tiara 2015 : 6) penggunaan media pembelajaran berbaasis TIK dalam proses pembelajaran dapat membantu guru dalam menghemat waktu, serta siswa dapat memahami materi dengan lebih mudah.

\section{Kesimpulan}

Berdasarkan hasil validasi E-learning berbasis moodle yang dilakukan oleh 8 validator didapatkan rata-rata semua aspek adalah $\mathrm{V}_{\mathrm{a}}=4,19$. Menurut kriteria kevalidan maka $E$ learning berbassis moodle ini dinyatakan valid. Setelah E-learning berbasis moodle ini dinyatakan valid kemudian dilakukan uji coba terhadap 21 warga belajar. Berdaarkan hasil ujicoba didapatkan rata-rata penilaian warga belajar terhadap E-learning berbasis moodle adalah $\bar{X}=3,31$. Menurut kriteria kepraktisan maka E-learning berbasis moodle ini dinyatakan praktis. Dari pernyataan diatas maka dapat diambil kesimpulan bahwa: “Elearning berbasis moodle yang dikembangkan Valid dan Praktis”. 
Pustaka

Asyar, R. 2011. Kreatif Mengembangkan Media Pembelajaran. Jakarta. Gaung Persada.

Caputi, V, \& Garrido, A. 2015. "Student-oriented Planning of E-Learning Content for Moodle", Jurnal of Network and Computer Applications, 53,115-127.

Kamil, Mustofa. 2009. Pendidikan Nonformal : Pengembangan Melalui Pusat Kegiatan Belajar Mengajar (PKBM) di Indonesia. Bandung: Alfabeta.

Manson, Robin dan Frank Rennie. 2010. Panduan Lengkap Memahami Dunia Digital dan Internet. Yogyakarta: Pustaka Baca.

Republik Indonesia.1989. Undang-Undang No. 2 tahun 1989 tentang Sistem Pendidikan Nasional. Sekretariat Negara. Jakarta.

Republik Indonesia. 2003. Undang-Undang No. 20 tahun 2003 tentang Sistem Pendidikan Nasional. Sekretariat Negara. Jakarta.

Republik Indonesia. 2013. Peraturan Menteri Pendidikan dan Kebudayaan tentang Penyelenggaraan Pendidikan Jarak Jauh Pada Pendidikan Tinggi. Menteri Pendidikan dan Kebudayaan Republik Indonesia. Jakarta.

Republik Indonesia. 2016. Peraturan Menteri Pendidikan dan Kebudayaan tentang Program Indonesia Pintar. Menteri Pendidikan dan Kebudayaan Republik Indonesia. Jakarta.

Sugiyono. 2016. Metode Penelitian Pendidikan. Bandung: Alfabeta.

Tiara. November 2015. Pengembangan Media E-Learning Berbasis Moodle Pada Kompetensi Dasar Jurnal Khusus untuk Siswa Kelas XII IPS Semester Gasal di SMA Negeri 4 Jember. Prosiding Seminar Pendidikan Ekonomi \&Bisnis, di Universitas Sebelas Maret Surakarta.

Thiagarajan, Sivasailam, dkk. 1974. Instruction Developmen for Training Teacher of Exceptional Children. Mineapolis, Minnesota: Indiana University Bloomington

Wibawanto, Hari. 2017. Instrumen Evaluasi Kualitas Pembelajaran Daring dalam SPADA Indonesia. Semiloka Pembelajaran Daring di Perguruan Tinggi Banjarmasin dan Surabaya. 